few show the first isolated symptoms of bromism. For the future welfare of the individual, the gastrointestinal and mental derangements from the injudicious use of the bromids are of greater importance than skin lesions.

\section{TYPES OF INSOMNIA AND TREATMENT WITHOUT DRUGS.}

\section{JAMES T. FISHER, M.D.}

Professor of Nervous and Mental Diseases, College of Physiclans
and Surgeons. LOS ANGELES, CAL.

Conspicuous among the disorders which play a prominent rôle in undermining our health and destroying our peace of mind are the various types of insomnia and pathologic sleep.

Physiologic sleep is simply a period of resting for all our organs, their functions being markedly lowered, central control diminished, and changes of reconstruction occurring in our nervous equilibrium. The nervous patient sleeps badly, but the nature of the insomnia varies in many ways. Some go to sleep the moment they lie down, only to awake an hour or two later, to toss throughout the night, and possibly to doze off at the hour when they should awake. Others sleep well till the first peep of day, rising ill-humored and cross, having lost two of their nine hours' sleep. Some patients apparently never sleep and remain calm and comfortable the entire night, get very restless and provoked, get up and walk around the room or take a bath or read a book, but all to no avail, till 2 or 3 o'clock in the morning, when they fall asleep from sheer exhaustion. Some go to bed good natured, but gradually take an extremely pessimistic view of life, and remain in this psychic discomfort for many hours. Others go to sleep, but are disturbed by dreams and nightmares and have a constantly agitated sleep the entire night.

\section{PATHOGENESIS OF INSOMNIA.}

What may we rationally consider the pathogenesis of insomnia and these varied mental states which give rise to the disturbing dreams?

Insomnia is a continuation of the molecular vibration which is normal during cerebral activity, the result of too vivid sensorial impressions. It may be a sign of disturbed nutrition and alterations in the cerebral circulation. It follows naturally that any intoxication may sufficiently irritate and excite our "sleeping centers" to the extent that sleep is impossible, and set in discordant vibration the delicate cells in our frontal lobes which preside over and control our acts and thoughts.

The occurrence of painful and disturbing dreams may certainly be considered an abnormal mental condition, and a symptom which should attract our attention and be of distinct value in estimating the nature of the nervous trouble from which the patient may be suffering. These distressing dreams are generally the result of fatigue and the continuance of unhappy mental states which are merged into the sleeping state. They do not depend on our mental condition at bedtime, but on some unpleasant feature or worry, which may have been in our mind days or weeks previous. Painful and distressing dreams accompanied by a restless and unhappy sleep constitute not infrequently one of the very early symptoms in neurasthenia of the cerebral type. Dreams, good or bad, are merely the manifestation of the working of the subconscious mind. Memory being an adjunct of this subconscious mind, dreams are not con- fined necessarily to events of recent date. These dreamlike states may so frighten the patient that recourse to normal sleep is impossible.

\section{TYPES OF INSOMNIA.}

There are several varieties or types of insomnia:

1. The melancholy type of insomnia is often met in many different degrees. Here the patient is apprehensive of some calamity, is fearful of impending danger, and in a vague sort of way believes that he has been indiscreet in the past and is now just beginning to pay the penalty. He is possessed of preoccupying obsessions which revolve in his mind and cause wakeful visions of unpleasant scenes. It is observed more especially in persons having a neurasthenic mentality and who react quickly to their own autosuggestions.

2. Another and rarer type is made up of a class of individuals, usually literary in their tastes, who will quickly go to sleep and rest well for a few hours and often awaken with a start as from a dream and remain awake the remainder of the night, lying peaceful and quiet, often with closed eyes, endeavoring to settle problems of different kinds, or initiating ideas for some future event.

3 . There is still another class, formed of people who have periods of from four to six weeks in which they never sleep, but simply lie awake during the entire night. They are not happy, nor can they tell what troubles them. It is an indefinable something which simply shuts out all sleep. This, in a measure, is analogous to periodic insanity and its cure is attended with more than ordinary difficulty. It is almost always seen in persons possessing a marked neuropathic personality and in individuals of more than ordinary mental training.

\section{TREATMENT WITHOUT DRUGS.}

In the treatment of these psychoses, for truly such they are, one must remember that drugs and physical measures are of very small utility when they are given with the idea that a permanent cure will follow. They may relieve temporarily, but their continued use has in many ways been most harmful and may leave the patient in the deplorable condition of chronic insomnia. Many of the acute psychoses are markedly relieved by hydrotherapy-the hot wet sheet in particular-and even the hydrobromate of hyoscin has its place; but to cure this chronic sleepless patient one must be cognizant of the underlying cause, and not only know what it is but be able to counteract and to annul the offending factor.

To be in close touch and to have the entire confidence of the patient, to have him feel that you are the master of the situation, is imperative. But this must not be undertaken in any careless or flippant way. Intelligent explanation of the nature and cause of his worry and fear, of the value of kind and noble thoughts and the complete relaxation of body and soul, must be made seriously and with conviction. If the physician does not believe this himself, it is useless merely to repeat the instructions. One can never convey conviction to a patient without its being deeply rooted in himself. On careful questioning we often find definite fears or phobias of different degrees and intensity. Of all the mental states, fear is the most pernicious. The patient dreads the night, he knows he can not sleep, he says so to himself a thousand times, naturally his oft-repeated suggestion is effective and he does not sleep. This autosuggestion is innocently and unconsciously maintained and is a prolific cause for inability to find refreshing sleep. 
The treatment in such cases is most simple, is, indeed, so simple that most of us scorn to use it. The remedy is counter-suggestion, a convincing assurance that sleep will surely come. Teach the patient a wholesome philosophy, which consists in taking hold of things by the right end, and sleep will follow, as night the day.

In starting the treatment, to secure additional confidence one may suggest a warm foot bath on retiring, or a glass of hot milk, or some slight diversion, but if continued the patient forms a bad habit, and soon comes to require all these little extras which, in a measure, seem to lessen the effect of the direct suggestion.

The citation of cases illustrative of some different types of insomnia, together with their treatment, will be self-explanatory.

CASE 1.-Dr. C., a retired army officer, was referred to me by Dr. Swift. This patient had a most obstinate case of insomnia, the sleeplessness being a symptom of the disease for which he had been retired three years previously, viz., neurasthenia. He had been treated for this by many physicians, and at the time I first saw him was taking dram doses of sulphonal, which sometimes gave him three hours sleep. His wife told me with tears in her eyes that he had taken "tons of hypnotics, and had tried everything, but was only getting worse and becoming a physical wreck."

Treatment.-I put him in a hospital away from his wife and children, gave him no drugs whatever, and within a period of less than five weeks he was sleeping eight hours each night, and studying many hours each day, preparing for his examination before a state board. For ten days his only treatment consisted in daily visits to my office, where he was assured that each night he would sleep better than the night before, and would soon be able to return to his home. My instructions were to go to bed at 9 o'clock, to shut the eyes, and to play he was asleep, and though he felt wideawake, to lie perfectly still by force of will power. Each day or two he admitted that he was getting control over his insomnia. He used no hypnotics.

CASE 2.-W. H. W. was referred to me by Dr. Lobingier. He suffered from insomnia to the extent that he had to give up a large law practice in an eastern state and come to this climate, hoping he might improve. Mr. W. had certain phobias and fixed ideas regarding his mental state, which were exceedingly difficult to overcome. He would lie awake two-thirds of the night, endeavoring to go to sleep, but all the time he would say to himself, "It's no use; I can't go to sleep." In other words he could not go to sleep because he said he could not; a typical case of autosuggestion. He had at times a little palpitation. He had been in this condition for a period of about five years, and had recently had " $\pi$ course" of christian science.

Treatment.-An improvement was noticed in his insomnia as soon as he felt convinced that he had no organic heart trouble, the fear of which had caused him no small amount of worry. I wrote out the following sentence on a slip of paper, with instructions to read it many times during the day and evening: "I'm feeling fine. I'm going to get well. I'm going to sleep sound all night long." No other treatment was used except at an occasional visit at my office I would assure him that he looked fine and would soon return to his work all well. $\mathrm{He}$ improved very slowly for the first four weeks. Three times I had to renew his prescriptions, which he considered a joke, when one day he told me he was much better, that his fears has disappeared and sleep was normal.

CASE 3.-Mrs. M., aged 50, came to me from Long Beach for an unusual case of insomnia. She said that she never slept an hour in her life that she knew of since the age of 21 , never suffered any discomfort therefrom, and merely came to me partly from curiosity to see how it would seem to sleep normally. I inquired of her husband (not in her presence), a very intelligent retired banker, regarding his wife's statement, and he surprised me by saying during the twenty-three years he had been married he had never seen his wife asleep.

Treatment.- In this case I had no obsessions or bad habits to correct, and had to rely on post-hypnotic suggestion. I placed her in a moderate degree of hypnosis, while sitting in a rocking-chair, and repeated over and over that at 9 o'clock that evening she would feel very sleepy; that she would go to bed and go to sleep, and sleep soundly all night, and the follow. ing night, and that in two days she would come to my office at 4 o'clock. At the appointed time the lady appeared, and on asking her why she came at 4 instead of 2 , as she did the first time, she said she did not know, only that something told her to come at that hour. She further said that she went to bed and slept soundly six hours the first night, beginning at $\theta$ o'clock, and the next night she slept eight hours. For five weeks she came once a week, as she said jokingly, for a little nap, and during this period, and since, she sleeps from six to nine hours each night.

The rational treatment of any mental disorder must, of necessity, be a mental or suggestive treatment, and that any treatment which entirely leaves out this important factor must assuredly be a failure. Whether intentionally or not, we all use a certain amount of suggestion, and it is this factor which gives us success, very often when we insist that this is due to the favorite drug.

The majority of insomnias are distinctly of mental origin, and their successful treatment must be through avenues directed to overcoming false ideas and replacing fear with healthful, quieting thought and the removal of irritants which directly or indirectly affect the minds of the patients.

THE NATIONAL FORMULARY.

its attitude to PHaRmaCeUtical PRoprietaries.*

\section{LEWIS DIEHL, Рн.M.}

Professor of Pharmacy in the Louisville College of Pharmacy; Chairman of the Committee on National Formulary of the American Pharmaceutical Assoclation; Member of Council on Pharmacy and Chemistry of the American Medical Association.

LOUISVILIE, $\mathbf{K X}$.

In the address of a pharmacist to physicians it is unavoidable that his professional bias shall in a greater or less degree dictate the thoughts he designs to express. The subject of my address, however, is one on which we as pharmacists and you as physicians meet on common ground; it is a subject on which we are mutually and equally interested, and one which we must carefully consider and clearly understand if we wish, in some degree at least, to ameliorate conditions which have wellnigh succeeded in annihilating professional pharmacy, without a compensating benefit to the profession of medicine. The defenders of these untoward conditions tell us that these are the inevitable results of modern prog. less and invention; that the development of pharmacy has gone hand in hand with the advance in medicine; and they even go so far as to claim that only by this development of pharmacy the advance in modern therapy has bcome possible. I should be loth to admit that I have grown too old to appreciate the modern advances that have been made in both domains; but it is a debatable question in what direction we can concede that a true advance has been made in that of pharmacy. Surcly not professionally; for, with all proper respect for the educational influence of colleges of pharmacy, the supervision of boards of pharmacy and the attempts by legal enactments to elevate the standard of pharmacy, the lamentable fact remains that pharmacy as a profession is degenerating.

It is not my purpose to discuss this question, however, in all its bearings, but to confine my observations in a

* Read in the Section on Pharmacology of the American Medica Association, at the Fifty-serenth Annual Session, June, 1906. 